\title{
Sobre as singularidades da metafísica da moral em Schopenhauer e a significação do fenômeno de compaixão
}

\author{
About the singularities of moral metaphysics in Schopenhauer and \\ the meaning of the phenomenon of compassion \\ Anerson Gonçalves de Lemos \\ Mestrando em Filosofia pela UFSM sob a orientação do Prof. Dr. Flávio Williges e bolsista do \\ CNPq. Especialista em ética pela UFAM. \\ E-mail: anersonlemos@hotmail.com
}

\begin{abstract}
Resumo: Neste artigo, apresentaremos uma caracterização e defesa da interpretação fenomenológica da filosofia moral schopenhaueriana enquanto um de seus elementos diferenciadores na tradição idealista pós-kantiana e algumas de suas contribuições para ampliação da discussão ética para além dos limites do racionalismo moderno, a partir da inclusão da interpretação dos fenômenos como componente da reflexão moral. Iniciaremos discutindo a base conceitual utilizada por Schopenhauer, mostrando que sua compreensão da exigência de uma análise empírica ou fenomenológica remonta a Descartes e recebe a contribuição decisiva de Kant, cuja proposta de um idealismo transcendental radicaliza a discussão sobre a natureza subjetiva de nosso conhecer. Por fim, apresentaremos a análise de Schopenhauer sobre o conceito de compaixão, a fim de mostrar sua forma de investigação dos sentimentos a partir de uma interpretação dos fenômenos como base de significação, isto é, como uma "fenomenologia" ou "hermenêutica", pois consiste em uma investigação metafísica imanente sobre o significado dos fenômenos.
\end{abstract}

Palavras-chave: Metafísica; Fenomenologia da moral; Compaixão.

\begin{abstract}
In this article we present a characterization and defense of the phenomenological interpretation of Schopenhauer's moral philosophy while one of its differentiating elements in post-Kantian idealist tradition and some of his contributions to expanding the ethical discussion beyond the limits of modern rationality from the inclusion of interpretation of phenomena as a component of moral reflection. We shall begin discussing the conceptual basis used by Schopenhauer demonstrating that his understanding of the requirement of an empirical or phenomenological analysis dates back to Descartes and receives the decisive contribution from Kant, whose proposal for a transcendental idealism radicalizes the discussion of the subjective nature of our knowledge. Finally, we present Schopenhauer's analysis of the concept of compassion in order to show his form of investigation of sentiments based on an interpretation of the phenomena as a basis of significance, meaning, as a "phenomenology" or "hermeneutics", since it consists of an immanent metaphysical inquiry into the meaning of the phenomena.
\end{abstract}

Keywords: Metaphysics; Phenomenology of moral; Compassion.

\section{Considerações preliminares}

A reflexão de Schopenhauer, sob o ponto de vista da história das ideias (e conforme ele próprio se identifica), insere-se no idealismo alemão que sucedeu Kant. 
Entretanto, embora esse primeiro figure juntamente a Fichte, Schelling e Hegel como um dos principais representantes do idealismo alemão, em alguns aspectos, suas reflexões são reconhecidamente tão singulares que há sempre que se fazerem muitas ressalvas quando o inserimos nesse contexto.

Uma parte significativa de tal singularidade consiste na concepção schopenhaueriana de uma metafísica imanente e seus desdobramentos no campo da filosofia moral que busca a superação dos modelos apriorísticos propostos pelos principais representantes do idealismo pós-kantiano e sugere que nos voltemos para os próprios fenômenos, seguindo-lhes uma investigação analítica, por meio da qual podemos interpretá-los. Mostraremos, portanto, o que possibilita uma nova forma de abordagem das questões em Schopenhauer é sua atitude antidogmática, como explica Cacciola ${ }^{1}$, ele reage ao dogmatismo no qual caiu à própria filosofia crítica de Kant e a continuação dela no idealismo que a sucedeu.

Nesse sentido, chamamos atenção para singularidade do método de investigação schopenhaueriano, que embora proposto como uma metafísica não prescinde da análise dos fenômenos, mas os valoriza. Essa sua concepção, que é denominada por alguns de seus interpretes atuais como uma "metafísica hermenêutica", ou como "hermenêutica da existência" ou ainda como uma "fenomenologia da moral",2, não somente diferencia profundamente a reflexão de Schopenhauer, mas a aproxima de modelos de investigação mais contemporâneos e permitindo que sua análise seja retomada por filósofos contemporâneos, como, por exemplo, Michel Henry ${ }^{3}$.

Para apresentar os aspectos fundamentais da ênfase no caráter fenomenológico e hermenêutico da filosofia de Schopenhauer, iniciaremos apresentando dois aspectos históricos fundamentais de sua filosofia: a herança cartesiana e kantiana. Procuraremos mostrar que Schopenhauer faz uma interpretação ou subverte essa herança na direção de uma filosofia fenomenológica. Dizer que sua filosofia é uma fenomenologia significa dizer que os fundamentos da filosofia e metafísica de Schopenhauer são uma

1 Cf. CACCIOLA, M. L. Schopenhauer e a questão de dogmatismo, p. 20.

2 A denominação "metafísica hermenêutica" é apresentada por Spierling (2010, p. 24), enquanto que "hermenêutica da existência" é sugerida por Birnbacher (2006, p. 177), e "fenomenologia da moral" é proposta por Philonenko (1989, p. 234).

3 O filósofo francês Michel Henry, em sua obra Genealogia da psicanálise: o começo perdido, é um dos fenomenólogos que chamam atenção para a contribuição de Schopenhauer em relação às mudanças de perspectivas das metodologias de investigação filosófica. 
“interpretação do fenômeno", e não apreensões a partir de dados apriorísticos, como parece ter sido o caso em Descartes e Kant.

O texto está dividido em duas partes. Na primeira parte, apresentamos uma análise das questões que fundamentam epistemologicamente a reflexão de Schopenhauer sobre a moralidade como uma abordagem metafísica e imanente ao mesmo tempo. Com essa finalidade, revisitamos a leitura do filósofo da discussão moderna sobre a questão da subjetividade e objetividade, retrocedendo ao que ele considera terem sido contribuições fundamentais sobre o tema na epistemologia da modernidade, ou seja, as reflexões de Descartes e Kant, e ao mesmo tempo a algumas de suas principais consequências e ressonâncias de dessas reflexões em sua própria doutrina filosófica.

$\mathrm{Na}$ segunda parte, analisamos as implicações de uma nova concepção de metafísica para a reflexão moral de Schopenhauer. Para isso, escolhemos analisar de forma mais específica o conceito de compaixão, o qual se discute a partir da singularidade da concepção metafísica schopenhaueriana, que envolve os elementos fenômeno, interpretação e significação.

\section{A metafísica como "ciência do fenômeno"}

Embora a atitude antidogmática de Schopenhauer que mencionamos acima nos lembre de imediato a filosofia crítica de Kant, paradoxalmente ela encontra sua origem e afinidade primeiramente em Descartes, que segundo Schopenhauer foi quem expressou pela primeira vez com a devida propriedade em suas dúvidas céticas que nosso acesso à realidade consiste essencialmente em representações, segundo ele, algo negligenciada inclusive pelo autor da Crítica da razão pura ${ }^{4}$.

Nesse sentido, para mostrar que Schopenhauer deu uma conformação nova para a metafísica, aproximando-a de uma fenomenologia, é essencial abordar essa sua apropriação da filosofia moderna. Segundo ele, o selo distintivo da filosofia da modernidade é a sua preocupação com o problema da subjetividade e da interioridade, conjugada sob o conceito de investigação transcendental. É nesse sentido que ele 
reconhece em Descartes aquele que praticamente inaugura o pensamento moderno, pois apresenta uma contribuição decisiva para a filosofia posterior, uma mudança radical que foi fazer a reflexão voltar-se para o sujeito. Por meio da preocupação com interioridade do sujeito cognoscente, Schopenhauer compreende que Descartes trouxe à baila a questão em torno da qual gira toda a filosofia moderna, a saber, o problema da subjetividade do conhecimento. Ele afirma:

\begin{abstract}
No entanto, o problema claramente reconhecido e expresso continua sendo o tema característico da filosofia moderna, depois que a reflexão necessária a esse objetivo foi despertada em Descartes, quando ele foi tomado pela verdade de que, antes de mais nada, estamos limitados à nossa consciência e de que o mundo nos é dado unicamente como representação $0^{5}$.
\end{abstract}

Vemos que, em Schopenhauer, a herança cartesiana é compreendida de antemão como uma assunção da imanência de nossas percepções à representação, isto é, ao fenômeno, dado que para ele os termos representação e fenômeno são intercambiáveis ${ }^{6}$. Assim, não é sem razões que essa concepção é apresentada na célebre frase de abertura de sua obra principal, $O$ mundo como vontade e representação, quando diz: "o mundo é minha representação"7 . É por conta da admissão de que a realidade sempre nos é dada como fenômeno que o autor de $O$ Mundo enfatiza que a formulação cartesiana "dubito, cogito, ergo sum" constitui a "única certeza da consciência subjetiva, em oposição à problematicidade de todo o resto" ${ }^{\prime}$. Dito de outro modo, o Cogito cartesiano torna claro que as nossas representações, ou seja, o conjunto de fenômenos pelos quais temos acesso à realidade constituem para quem as percebe, uma limitação em relação ao que seria o nosso conhecimento da realidade independentemente delas. Para Schopenhauer, portanto, a ciência desse fato deve levar-nos a um esforço para a superação da perspectiva subjetiva, a qual deve ser buscada voltando-nos para o que se apresenta de modo imediato na consciência, ou seja, a base da constituição do real.

Assim, para Schopenhauer, Descartes apresenta-nos tanto uma total imanência à nossa consciência subjetiva, quanto o caminho para uma possível tentativa de

5 SCHOPENHAUER, A. P/ Fragmentos sobre a história da filosofia. Tradução de Karina Jannini, p. 05.

6 Cf. Idem, p.ex. p. 27.

7 SCHOPENHAUER, A. MVR, p. 45.

8 SCHOPENHAUER, A. P/ Fragmentos sobre a história da filosofia, p. 45. 
superação, a saber, o caminho é uma "filosofia voltada para o interior, que parte do sujeito como dado imediato" ". É dessa forma que a discussão da interioridade do sujeito e igualmente a questão da subjetividade transcendental, à qual aquela remete, serão os elementos que, sob outra perspectiva, estarão presentes na metafísica schopenhaueriana.

Por meio desse primeiro panorama já é possível perceber que as características e singularidades da investigação da subjetividade, compreendida por Schopenhauer como filosofia transcendental, que, diga-se de passagem, constituem noções importantes na fenomenologia contemporânea, são consideradas por ele como de suma importância para investigação filosófica. Vejamos sua explicação:

Por esta (filosofia transcendental) eu entendo toda filosofia que parte do fato de que seu objeto mais próximo e imediato não são as coisas, mas somente a consciência humana das coisas, a qual, portanto, ninguém deve deixar fora de consideração. Os franceses a denominam de modo impreciso como méthode psychologique, em oposição ao méthode purement logique ${ }^{10}$.

É interessante observar aqui que, em Schopenhauer, a investigação transcendental é claramente identificada com a questão da consciência (noção que também adquire um papel de destaque na tradição fenomenológica), vista por ele como um dos problemas centrais da investigação filosófica, concebida, ao mesmo tempo, como o ponto de partida e o pressuposto fundamental de sua epistemologia ${ }^{11}$, assim como de sua metafísica e ética.

Entretanto, segundo o filósofo, o maior impulso para o campo de análise transcendental e, consequentemente, da metafísica é dado por Kant, especialmente a partir da Estética transcendental, juntamente com suas conclusões, aceitas por Schopenhauer como indubitavelmente verdadeiras. Ele afirma: "ela (a Estética transcendental) é o triunfo de Kant e pertence às muito poucas doutrinas metafísicas que podem ser consideradas como efetivamente provadas e como conquistas genuínas no campo da metafísica" ${ }^{12}$.

9 Idem, ibidem.

10 SCHOPENHAUER, A. P/ Sobre a filosofia e seu método. Tradução de Flamarion C. Ramos, p. 35.

$11 \mathrm{Cf}$. SCHOPENHAUER, MVR, p. 137.

12 SCHOPENHAUER, A. M/M, Tradução Maria Lúcia Cacciola, p. 214. 


\section{ANERSON GONÇALVES DE LEMOS}

Vejamos quais são e em que consistem especificamente para Schopenhauer as contribuições dadas por Kant; depois, por que ele as compreende como fundamentais para o campo da metafísica, uma vez que a sua concepção de metafísica não condiz inteiramente com a concepção kantiana.

As contribuições kantianas fundamentais no campo da filosofia transcendental, tantas vezes louvadas por Schopenhauer, estão para ele principalmente em sua demonstração de que as formas da nossa faculdade intuitiva, ou seja, as noções de espaço e tempo, assim como as relações necessárias que se estabelecem na intuição, a relação de causalidade, são atribuições do sujeito cognoscente, e não concernem propriamente à realidade em si, mas ao fenômeno. Como ele explica:

pertencem a esta (a faculdade de intuição) e não às coisas conhecidas por meio dela e não podem pois, jamais, ser uma determinação das coisas em si mesmas. Mas só pertencem ao fenômeno delas e como tal só são possíveis em nossa consciência do mundo exterior, presa a condições fisiológicas ${ }^{13}$.

Assim, nesse caso, são duas as consequências mais significativas daquelas conclusões de Kant para análise da filosofia transcendental e metafísica schopenhaueriana. A primeira diz respeito ao fato de que as estruturas que condicionam o fenômeno, por estarem presentes em nós a priori, "pertencem à parte subjetiva do conhecimento" ${ }^{14}$. Em segundo lugar, mas não menos importante, está o fato de que, por meio da delimitação do âmbito fenomênico, Kant distingue fenômeno de coisa em si.

Nesse sentido, uma vez que a análise a priori das estruturas intelectuais não nos conduz às coisas como elas são em si, mas só descreve as formas subjetivas fenomênicas, a partir de Kant, todos os expedientes usados pelo racionalismo dogmático moderno seriam insuficientes para responder satisfatoriamente a questão levantada por Descartes. Para Schopenhauer, portanto, é como se Kant nos colocasse novamente diante da dificuldade e profundidade do "abismo" revelado pelo filósofo francês entre objetividade e subjetividade do conhecimento.

Pode-se dizer que Schopenhauer enfrenta o problema proposto por Descartes a partir da contribuição e dos limites traçados pela filosofia crítica ou transcendental de

13 SCHOPENHAUER, A. $M / M$, p. 214.

14 SCHOPENHAUER, A. P/ Sobre a filosofia e seu método, p. 35. 
Kant, considerando que o caráter transcendental da análise kantiana se refere exatamente à sua imanência ao campo fenomênico, em oposição à proposta de transcendência, que seria uma inversão daquela primeira. Todavia, a filosofia da imanência transcendental adotada por Schopenhauer enfrenta o desafio de superar a subjetividade inerente ao campo fenomênico, supondo que essa possibilidade - isto é, o acesso ao aspecto objetivo do conhecimento - se dá por meio do outro polo da dualidade do real apresentada por Kant, ou seja, o campo da coisa em si.

Entretanto, a proposta de Schopenhauer para superação da subjetividade em grande parte consiste em seu esforço para tornar mais explícita e tangível a descrição do campo transcendental apresentado por Kant. Ele não se mantém dentro dos limites estabelecidos pela ortodoxia da metafísica kantiana - que estando presa ao modelo formal busca revelar as estruturas do campo transcendental por si só, quer dizer independente de seu conteúdo empírico - mas, compreende o conteúdo empírico, assim como os elementos fisiológicos que possibilitam sua percepção, como uma maneira de explicar e dar visibilidade aquelas estruturas ditas transcendentais.

Essa é, portanto, uma das marcas do método de investigação schopenhaueriano. Esse fato, embora já esteja expresso no primeiro tomo de $O$ mundo, é mais claramente delineado no segundo tomo da obra. Percebemos isso em observações como a seguinte, em que ele diz: "O eu lógico [Das logische Ich] ou ainda a transcendental unidade sintética da apercepção são expressões e explicações que não vão realmente servir para tornar o assunto mais compreensível" ${ }^{15}$.

Para Schopenhauer, todavia, a revelação e descrição das estruturas intelectoracionais do conhecimento por si só não nos conduzem ao fundamento de uma certeza, mas a forma mesma de apreensão da realidade por estruturas intelectuais a priori já nos coloca no campo da subjetividade. Além disso, há segundo ele, imperfeições inerentes ao próprio intelecto que tornam ainda mais relativas as percepções que temos do mundo. Imperfeições essas, que começam pela forma temporal e fragmentária como em geral percebemos os fenômenos, e vão até as variações individuais decorrentes de singularidades fisiológicas e anatômicas ${ }^{16}$. Todos esses fatores fazem com que os

15 SCHOPENHAUER, A. MVR II, p. 45.

16 Idem, p. 226-227. 
fenômenos se revelem variadamente condicionados pelo sujeito e a realidade empírica em si seja, segundo ele, "simplesmente aparência".

Dessa forma, são as conclusões de Schopenhauer sobre o âmbito transcendental que fazem com que o campo da representação seja um horizonte aberto às interpretações. Ou como ele explica:

O mundo intuitivo, por mais que se permaneça nele, não desperta escrúpulos nem dúvida no contemplador. Aqui não há erro nem verdade (confinados ao domínio abstrato de reflexão). Aqui o mundo se dá aberto aos sentidos e ao entendimento, com ingênua verdade como aquilo que é, como representação intuitiva, a desenvolver-se legalmente no vínculo da causalidade ${ }^{17}$.

Considerando que a estrutura por meio da qual os fenômenos se revelam não nos dá somente uma perspectiva, mas diversas, Schopenhauer conclui que a forma de ampliar nossa compreensão da realidade pode ser feita por meio da interpretação fenomênica. Compreende, assim, que são os próprios fenômenos que nos dão meios e condições para superá-los. Com isso ele reafirma sua concepção, admitidamente paradoxal, de que a metafísica deve ser imanente e mantém essa condição no âmbito da ética $^{18}$.

Assim, a identificação da atividade de síntese intelectual dos fenômenos com um processo fisiológico, corporal, é algo significativo nesse empreendimento, como observa Birnbacher:

[...] deve ser considerado um importante avanço o fato de Schopenhauer atribuir o desempenho sintético, que pela primeira vez possibilita a formulação de um mundo de fenômenos de maneira espacial, temporal e causal ordenada, ao cérebro empírico e não, conforme Kant, a um sujeito misterioso e transcendental ${ }^{19}$.

Embora deva ficar claro que, assim como para Kant, também em Schopenhauer o campo de atuação epistemológica e metafísico é o campo transcendental - ainda que, como temos visto, haja importantes desconformidades sobre o que corresponde exatamente a esse âmbito para cada um dos filósofos -, não há dúvida de que, para o

17 SCHOPENHAUER, A. $M V R$, p. 58.

18 Cf. SCHOPENHAUER, $M V R$, p. 355.

19 BIRNBACHER, Dieter. Arthur Schopenhauer: vontade e negação do mundo, p. 164. 
autor de $O$ mundo, o que representou um dos maiores retrocessos para a epistemologia e metafísica kantiana foi o seu caráter excessivamente abstrato. Por isso mesmo, como observa Spierling, no esforço para trazer a metafísica para questões mais concretas é que Schopenhauer "da un nuevo giro a la filosofia trascendental que va más allá de Kant"20.

Isso significa que, para Schopenhauer, a análise de Kant se preocupa meramente com a forma do fenômeno, deixando de lado seu conteúdo. A possibilidade de análise do fenômeno segundo sua forma e conteúdo é proposta por meio da inclusão de um elemento novo na análise transcendental, a saber, a análise do corpo, que Schopenhauer justifica da seguinte maneira: "toda a essência dos fenômenos dados, ou seja, do mundo corporal, não é absolutamente determinável a priori, ao contrário apenas a forma universal de seu fenômeno o é" ${ }^{21}$.

A inserção do elemento da corporeidade na análise transcendental faz com que o intelecto, ou cérebro, seja não somente a forma da constituição da realidade intuída, por meio de sua estrutura a priori, mas, uma vez que se encontra enraizado na natureza isto é, como parte de uma realidade que subsiste independentemente da representação -, o intelecto e sua estrutura transcendental passam a serem principalmente, os meios pelos quais se tem acesso ao aspecto objetivo do mundo, isto é, à coisa em si, a qual é também denominada por Schopenhauer de vontade. Essas suas conclusões deixam claro, além disso, que aquilo que vem a ser concebido por ele como coisa em si é algo bem diferente da proposta kantiana, um desdobramento fundamental para sua filosofia.

A corporeidade passa a ser uma noção de ampla relevância para a metafísica schopenhaueriana, pois, embora Schopenhauer apresente de maneira "unilateral" a estrutura a priori de representação no primeiro livro de $O$ mundo, sua metafísica propriamente dita, desenvolvida mais efetivamente no segundo livro da mesma obra, é apresentada a partir do fenômeno, considerando que na corporeidade este se manifesta em relação com a vontade e assim a revela. Por isso, segundo Schopenhauer, a

20 SPIERLING, Volker. Arthur Schopenhauer, p. 66.

21 SCHOPENHAUER, A. P/ Fragmentos sobre a história da filosofia, p. 132-133. 
metafísica que consiste no conhecimento da coisa em si deve partir não do sujeito nem do objeto, mas do próprio fenômeno, por meio da autoconsciência ${ }^{22}$.

Para essa nova concepção de metafísica, chama atenção Birnbacher quando diz:

O objeto da metafísica de Schopenhauer é o próprio fenômeno e não aquilo em que ela se fundamenta, eventualmente, transparece nela. Ela é realista no sentido bem não-metafísico pela maneira de descrever as coisas como elas de fato são, evitando idealizá-las ${ }^{23}$.

Podemos dizer que uma das maneiras pelas quais Schopenhauer evita que a metafísica se perca em divagações abstratas ou idealizações é deslocando o campo de investigação transcendental para a consciência, onde se manifesta enquanto fenômeno. E ele o faz considerando, ao mesmo tempo, tanto que a vontade ou coisa em si - objeto da metafísica - não se reduz às estruturas racionais intelectuais, por estas serem completamente heterogêneas a ela, quanto que a vontade não é perceptível a não ser por meio daquelas estruturas, ou seja, enquanto fenômeno. Dessa maneira, podemos dizer que sua análise fenomênica não prescinde da análise das estruturais racionais da representação, tanto é assim que ele define sua filosofia como uma forma de racionalismo ${ }^{24}$ e sua metafísica como uma "filosofia do espírito" ${ }^{25}$. Schopenhauer diz ainda a esse respeito:

Ela é um saber que tem por origem a intuição do mundo exterior real e as informações que a seu respeito nos revela o facto mais íntimo da nossa consciência, saber que depois é encerrado em conceitos precisos. É, por conseguinte, uma ciência de experiência ${ }^{26}$.

Portanto, para o filósofo de Frankfurt, superar o campo do fenômeno, ou seja, empreender uma investigação metafísica, não significa deixar de lado a experiência, ou estrutura intelectual por meio do qual ela se revela, mas interpretá-la nessa relação.

Nesse sentido, se Schopenhauer denomina sua análise metafísica de uma "ciência da experiência", poderíamos chamá-la de uma "fenomenologia" ou

22 Cf. SCHOPENHAUER, $M V R$, p. 69.

23 BIRNBACHER, Dieter. Arthur Schopenhauer: vontade e negação do mundo, p. 164.

24 Cf. SCHOPENHAUER, A. P/ Sobre a filosofia e seu método, p. 38.

25 SCHOPENHAUER, A. MVR II, tradução de Lobo Vilela, p. 45.

26 Idem, p. 66-67. 
hermenêutica? Haveria outras evidências textuais que apontariam nessa direção? Considerando que esse mesmo procedimento é utilizado por Schopenhauer em sua ética, buscaremos apresentar no que segue a assim chamada por Philonenko "fenomenologia da moral" de Schopenhauer ${ }^{27}$.

\section{A significação metafísica do fenômeno compaixão}

Considerando que a concepção de Schopenhauer apresentada acima propõe uma modificação na concepção tradicional no campo epistemológico e metafísico, que incorpora ou preserva um sentido fenomenológico de atenção à experiência, na medida em que interpreta a investigação transcendental a partir da ênfase na corporeidade e do dado da consciência, é necessário compreender também como se apresenta o desdobramento de sua proposta na filosofia moral.

De fato, alguns dos resultados mais originais da aplicação do método de investigação schopenhaueriano se encontram em sua ética. Isso porque para o filósofo esse é também o ponto culminante da epistemologia e metafísica, uma vez que os objetos de investigação mais importante da filosofia moral, a saber, o caráter individual, as motivações e as ações humanas que se manifestam em decorrência deles constitui para ele o reflexo mais perfeito do que é o mundo em sua essência.

Considerando, portanto, que o ponto de vista mostrado por meio da filosofia moral é para Schopenhauer aquele que "deve provar-se como o mais significativo de todos" (2005, p. 354); chamamos atenção para o fato de que uma leitura correta dos textos que envolvem essa temática exige um olhar ainda mais atento em relação à singularidade de seu método e as consequências dele para suas conclusões. E ainda mais em relação aos textos que foram escritos separadamente do desenvolvimento de sua metafísica. Essa é uma das questões para a qual chama atenção Philonenko quando escreve: "El corto ensayo titulado El fundamento de la moral indujo a error a los intérpretes de Schopenhauer, que se imaginaron que efectivamente había ahí un principio en un sentido cuasi-kantian",28.

27 Cf. PHILONENKO, Alexis. Schopenhauer: Una Filosofía de la Tragedia, p. 234.

28 Idem, p. 232. 
O equívoco mencionado por Philonenko torna-se mais frequente quando se trata do conceito de compaixão, isso porque a análise desse conceito nos remete diretamente à obra à qual ele se refere. Ou seja, a dissertação escrita em 1840, na ocasião de um concurso promovido pela Academia de Ciências da Dinamarca, uma vez que é ali que Schopenhauer desenvolve a explicação mais extensa e minuciosa sobre esse conceito. Aliás, essa sua a obra se detém de forma tão exclusiva ao conceito de compaixão que ele poderia perfeitamente fazer o que sugere Cartwright e ter a intitulado simplesmente como "On Compassion",29.

Por outro lado, embora encontremos nessa obra a elucidação de aspectos muito importantes sobre o conceito de compaixão - uma vez que o filósofo o apresenta como a base principal para elucidação do significado moral da conduta humana -, no que diz respeito ao caráter hermenêutico de sua metafísica, muitos dos intérpretes não observam as circunstâncias em que a discussão é apresentada ali.

Um exemplo desse caso parece ser a análise de Terence Irwin do conceito de compaixão, pois, ao concentrar-se na exposição desse conceito como ele é apresentado na dissertação de 1840, ele reduz sua interpretação sem considerar devidamente a dimensão metafísica dada ao conceito por Schopenhauer - dito de outro modo, sua significação. Assim, Irwin em muitas ocasiões toma a noção de compaixão schopenhaueriana como consistindo num sentimento subjetivo, tal como a noção havia sido tomada no empirismo inglês. Quando interpretamos essa noção a partir da ideia de uma fenomenologia moral, isto é, quando a apresentamos a partir de uma interpretação do fenômeno presente na autoconsciência, o sentido da compaixão assume outra conotação, bastante distinta daquela do empirismo, e aproxima-se mais da tradição oriental do budismo, que enfatiza a compaixão como uma atitude abrangente de reconhecimento do caráter indiferenciado de nossa natureza como vontade.

A análise que faremos aqui não pretende esgotar a posição defendida por Irwin, mas procurará basicamente mostrar que alguns dos problemas levantados por ele sobre o conceito schopenhaueriano de compaixão se explicam pela ausência da significação que lhe é dada quando em relação com seu sistema ético-metafísico, particularmente

29 CARTWRIGHT, E. David. Schopenhauer's Narrower Sense of Morality, p. 30. 
pelo não-reconhecimento do lugar e singularidade da metafísica interpretativa ou hermenêutica proposta pela filosofia schopenhaueriana.

Irwin começa seu estudo sobre a noção de compaixão analisando o princípio moral relacionado a ela, que, segundo a formulação de Schopenhauer, diz: "não faças mal a ninguém, mas antes ajuda a todos que puderes" ${ }^{30}$. Irwin explica que se a proposta schopenhaueriana exige uma consideração com o bem-estar ou sofrimento alheio, "essa atitude é necessária para assegurar a anuência do princípio fundamental da moralidade", e que, portanto, "aceitamos esse princípio, segundo Schopenhauer, em razão da compaixão" 31 .

A forma como Irwin conduz a explicação sobre a "relevância da compaixão" nos leva a compreender que ela é a base para moralidade para Schopenhauer porque a partir dela seria possível prescrever um princípio moral fundamental. Ele não explica, entretanto, que Schopenhauer apresenta a formulação desse princípio moral, sobretudo, para mostrar que tal elaboração não pode confundir-se com a explicação de um fundamento da moral, diferenciação que, conforme o filósofo alemão, não é observada por Kant.

Ele deixa de lado, assim, a observação de Schopenhauer que antecede a apresentação desse princípio, a qual explica que o significado cujo princípio moral adquire pode variar de acordo o caráter da doutrina que o expressa, podendo assim consistir na "expressão mais concisa para o modo de agir que ela prescreve, ou, se ela não tiver uma forma imperativa, para o modo de agir ao qual ela reconhece valor moral" 32 .

Schopenhauer claramente insere-se na segunda alternativa ${ }^{33}$; mesmo assim, Irwin testa a proposição apresentada por ele como se fosse análoga à fórmula imperativa kantiana $^{34}$, como se parte da significação moral da compaixão consistisse no fato de que por meio dela se pudesse elaborar o princípio da ação correta e este estivesse ainda relacionado uma funcionalidade social.

30 Cf. IRWIN, T. The Development of Ethics: a historical and critical study, p. 272. A tradução da máxima schopenhaueriana, originalmente apresentada em latim na dissertação Sobre o Fundamento da Moral, é de Maria Lúcia Cacciola.

31 Idem, p. 272.

32 SCHOPENHAUER, A. $M / M$, p. 43 , grifos meus.

33 Cf. SCHOPENHAUER, MVR, p. 234.

34 Cf. IRWIN, T. The Development of Ethics: a historical and critical study, p. 273. 


\section{ANERSON GONÇALVES DE LEMOS}

É também nessa direção que Irwin apresenta uma segunda interpretação da natureza da compaixão, mostrando que, em sua explicação psicológica, a qual Schopenhauer discute com Cassina, ele compreende a compaixão como fenômeno individual, assim, sua interpretação desse conceito como fundamento da moral estaria muito próximo de uma espécie de sentimentalismo à maneira de Hume e Smith. A interpretação de Irwin permanece limitada nesse aspecto, pois, ao analisar a compaixão como fundamento da moral, ele o faz em comparação com a ética kantiana, no sentido de relacionar a compaixão com um pressuposto da noção de moralidade enquanto ação correta, algo que não estava mais no escopo de Schopenhauer.

Ainda quando se refere ao aspecto metafísico da fundamentação da filosofia, Irwin a apresenta como uma mera continuidade da doutrina metafísica kantiana, deixando de lado, portanto, um dos aspectos mais inovadores da proposta schopenhaueriana, que como já explicamos, consiste notadamente em sua compreensão da metafísica enquanto hermenêutica do fenômeno. Assim, o filósofo inglês chega a ver na "ênfase de Schopenhauer sobre a fenomenologia da compaixão" ${ }^{35}$ uma forma de limitação em sua explicação metafísica sobre o fundamento da moral, quando na verdade, segundo a concepção de Schopenhauer, quando mais detalhado e preciso for a explicação fenomenológica de determinado aspecto da moral mais claro se torna sua significação metafísica.

De fato, a análise fenomenológica da compaixão apresentada por Schopenhauer na dissertação Sobre o Fundamento da Moral consiste em seu esforço para compensar a ausência da estrutura metafísica que permite interpretar o fenômeno como algo que o supera. Dessa forma, ele se limita a explicar o significado do fenômeno moral do ponto de vista externo, segundo o pressuposto kantiano, que preconiza que a ação moral tem como condição principal um motivo não-egoísta, que é o que, segundo ele, se verifica nas ações movidas pela compaixão; e, do ponto de vista interno, como o sentimento psicológico de contentamento que experimentamos quando agimos compassivamente, conhecido como "aplauso da consciência".

Uma interpretação mais adequada para a proposta schopenhaueriana parece ser a fornecida por Christopher Janaway, quando propõe que a ética proposta por

35 Idem, p. 276. 
Schopenhauer se relaciona com uma determinada maneira de ver o mundo, ou em "ver o mundo na perspectiva correta" ${ }^{36}$, e assim também o significado moral da conduta se referiria a tal perspectiva. Essa concepção se ajusta de forma mais adequada à concepção de uma ética de caráter descritivo e hermenêutico como a proposta por Schopenhauer, que considera que mesmo tendo a ação humana como objeto de investigação - quando se poderia chamar a filosofia de "prática" -, ainda nesse âmbito ela permanece sendo estritamente "teórica" 37.

Daí a comparação feita por Schopenhauer no final da introdução a sua ética em O mundo, parágrafo 53, quando ele compara a filosofia à arte em relação ao fato de que esta tem como objeto "o ser do mundo sempre igual a si e a aparecer em todas as relações, porem sem se submeter a estas, numa palavra, as Ideias mesmas" ${ }^{38}$. Se considerarmos que, segundo ele, a arte nos conduz a ver as coisas da perspectiva a qual ele denomina com as palavras de Espinosa como: "ponto de vista da eternidade" 39 , compreenderemos que a filosofia - a sua maneira, e especialmente por meio da ética -, tem para ele também a função de descrever um ponto de vista semelhante.

Nesse sentido, ao colocar essas questões segundo essa perspectiva, percebemos que o significado dos problemas éticos analisados por Schopenhauer adquirem outra conotação, diferentes daquela enfatizada por Irwin, pois assim eles se encontram relacionados ao seu escopo genuíno, ou seja, segundo uma significação metafísica. Esse fato se torna claro quando comparamos as suas explicações sobre o que determina a conduta moral segundo uma base empírica, e segundo uma base metafísica. Observemos os seguintes exemplos considerando cada uma delas.

Na dissertação Sobre o Fundamento da Moral, em que sua explicação se restringe a uma explicação empírico-analítica se lê: "Este conhecimento, para o qual, em sânscrito, a expressão corrente é "tat-tvam-asi”, quer dizer, "isto é tu”, é aquilo que irrompe como compaixão, sobre a qual repousa toda virtude genuína “40.

Em $O$ mundo como vontade e representação, onde a sua explicação é livremente reconduzida a seu verdadeiro escopo, lê-se: “a frequentemente mencionada fórmula dos

36 JANAWAY, Christopher. Schopenhauer, p. 109.

37 Cf. SCHOPENHAUER, MVR, p. 353.

38 Idem, p. 354.

39 Cf. Idem, p. 247.

40 SCHOPENHAUER, A. $M / M$, p. 219. 
brâmanes, “Tat tvam asi”, quer dizer, 'este é você'. Toda virtude genuína procede do conhecimento imediato e intuitivo da identidade metafísica de todos os seres" ${ }^{41}$.

Enquanto que na exposição empírico-analítica, embora a compaixão explique os fenômenos morais, ela se mostra como um processo misterioso, na exposição metafísica, tanto o próprio sentimento de compaixão, como o seu significado moral são elucidados. Essas perspectivas, entretanto, não se opõem, mas, se complementam. Isso porque na metafísica proposta por Schopenhauer não há fundamentos exteriores aos próprios fenômenos (ou aparências) que garantam que aquilo que são revelados por meio deles são de fato conhecimentos verdadeiros. Todavia, o sentido de suas verdades é dado por meio da interpretação dessas aparências, pois é dessa maneira que ele elabora sua metafísica. Por essa razão, a metafísica da vontade e os conceitos a ela pertencentes devem ser analisados sempre em relação com seu caráter hermenêutico.

O fator diferenciador da análise de Janaway do conceito de compaixão consiste em considerar o sentido dado pelo viés metafísico e hermenêutico da ética schopenhaueriana. Por essa razão, além de levar conta os aspectos fenomenológicos patentes na exposição empírico-analítica do conceito, ele enfatiza os aspectos teóricodescritivos inerentes à filosofia moral de Schopenhauer. Nesse sentido, Janaway analisa a compaixão também como um fenômeno que nos dá uma forma privilegiada de conhecimento da realidade, ele diz: "a compaixão é caracterizada, em última análise, como reflexo de uma visão de si e da natureza da realidade que difere da que está implícita no egoísmo e que é superior a ela" ${ }^{42}$.

Por essas razões, é importante compreender que, ainda que exposto de forma empírico-analítica, o fundamento da moral vinculado à compaixão não se destina a prescrições de modos de agir corretos, mas seu verdadeiro significado reside no fato de que a compaixão revela um conhecimento superior da realidade, que se confirma na conduta moral. Da mesma forma que as motivações antimorais e ações que elas determinam nos dão a conhecer o oposto disso.

A explicação de Janaway é esclarecedora nesse ponto, pois ela mostra para onde de fato a filosofia moral schopenhaueriana se direciona, esclarecendo que, apesar de sua pretensão de superar o âmbito empírico e analisar as condutas de um ponto de vista

41 SCHOPENHAUER, A. MVR II, p. 232.

42 JANAWAY, Christopher. Schopenhauer, p. 121. 
metafísico, ela o faz evitando arbitrariedades, pressupostos e sem prescrever regras de conduta. Há nessa interpretação a compreensão de que o caráter hermenêutico da metafísica de Schopenhauer é um elemento essencial no seu propósito de elaborar uma ética teórico-descritiva. Seguindo esses direcionamentos, Janaway chega a seguinte conclusão sobre o conceito schopenhaueriano de compaixão: “a compaixão é uma coisa boa não apenas porque tende a reduzir a quantidade de sofrimento no mundo como porque é a personificação de um quadro metafísico mais verdadeiro" ${ }^{43}$.

Portanto, embora a análise da compaixão enquanto fenômeno seja um aspecto importante da explicação dada por Schopenhauer às questões morais, ela não a esgota, pois é preciso lançar luz sobre o próprio sentimento de compaixão, ou seja, é necessária uma significação do fenômeno dada a partir de sua interpretação; é o que exige Schopenhauer quando escreve:

\begin{abstract}
Até agora, demonstrei a motivação moral como fato e mostrei que só a partir dela podem surgir a justiça desinteressada e a caridade genuína. Para fundar a ética isto é suficiente, [...] Entretanto, vejo muito bem que o espírito humano ainda não encontra aí seu contentamento e repouso [...] também aqui o espírito está diante de um fenômeno originário que esclarece tudo o que é compreendido sob ele e o que dele segue, mas ele próprio permanece inexplicável ${ }^{44}$.
\end{abstract}

Em concordância com Janaway, e contra a leitura de Irwin, cremos que uma valorização maior da atenção de Schopenhauer aos fenômenos revela a compaixão não como um sentimento individual, despertado nos sujeitos frente à condição de sofrimento dos outros. A noção de compaixão de Schopenhauer parece ser mais adequadamente entendida como uma interpretação metafísica de uma força mais abrangente do que um sentimento individual; ela é, na expressão de Spierling, "a unidade total de todos os seres vivos"45. A fenomenologia moral de Schopenhauer revela, assim, que a compaixão, muito mais do que um imperativo racional ou um sentimento particular, é um sentido de pertença ou partilha humana universal, de caráter intuitivo e préconceitual. Como diz Spierling, numa direção que confirma o sentido fenomenológico que estamos enfatizando,

\footnotetext{
43 Idem, ibidem.

44 SPIERLING, Volker. Arthur Schopenhauer, p. 137.

45 Idem, ibidem.
} 
Na compaixão, esse grande mistério da ética, coisa que, não obstante, ocorre diariamente, a consciência vislumbra que meu ser interior e verdadeiro existe em cada ser vivo de maneira tão direta como se manifesta a mim em minha consciência própria. Essa consciência préconceitual e intuitiva, na qual caem os limites da pluralidade e da diversidade, as fronteiras do eu e do tu, é a compaixão. Sobre ela sozinha se apóiam todas as virtudes, especialmente a justiça e o amor aos seres humanos ${ }^{46}$.

Nesse sentido, a compaixão fenomenológica de Schopenhauer não é um fundamento kantiano tradicional, nem um sentimento corriqueiro, mas um estado de abertura da consciência, um estado de consciência de "amor transparente e altruísta a tudo o que vive" ${ }^{47}$. Ela é um reconhecimento do verdadeiro eu, algo que permanece oculto na interpretação de Irwin.

A razão por que as interpretações como a de Irwin tendem a simplificar e empobrecer o conceito schopenhaueriano de compaixão é que elas não dão a devida atenção a fato de que, embora haja uma análise fenomênica na dissertação Sobre o Fundamento da Moral, ela não se conecta plenamente a uma significação moral metafísica proposta pelo sistema filosófico de Schopenhauer. Isso em razão de que ela realmente carece de tal conexão que apresente a interpretação do fenômeno da compaixão de uma perspectiva metafísica, pois como bem observou Roger ${ }^{48}$, essa questão pode ser considerada como uma lacuna na obra do filósofo. Observamos, por exemplo, que ele não escreve separadamente uma metafísica da compaixão, ou uma metafísica do "amor puro ( $\alpha \gamma \alpha \pi \eta$, caritas)", como o faz, por exemplo, em relação ao amor erótico, sobre o qual ele escreve uma Metaphysik der Geschlechtsliebe ${ }^{49}$.

\section{Idem, ibidem.}

47 Idem, ibidem.

48 Roger observa que o tema da compaixão não é retomado de forma minuciosa no segundo tomo de $O$ mundo como vontade e representação, nem nos escritos dos Parerga e paralipomena, o que, segundo ele, pode ser explicado pelo fato de que o autor não gostaria de repetir a reflexão desenvolvida na dissertação Sobre o Fundamento da Moral, que, entretanto, se atém ao aspecto fenomênico (ROGER, 2001).

49 Schopenhauer escreve acréscimos explicativos no segundo tomo de $O$ mundo como vontade $e$ representação, nos quais são esclarecidas várias questões por ele tratadas no primeiro tomo desta obra, e em outras por ele publicadas. Muitas destas questões recebem explicações a partir de sua concepção de metafísica. Entre estes acréscimos, ele desenvolve no capítulo XLIV do segundo tomo de sua obra principal uma "Metaphysik der Geschlechtsliebe", traduzida para língua portuguesa por Jair Barbosa com o título de "metafísica do amor". Entretanto, esta tradução não especifica tão bem o termo "Geschlechtsliebe", que, traduzido literalmente, significa "amor sexual", como o traduziu Eduardo Ribeiro da Fonseca no segundo tomo de $O$ mundo. Pois, assim, é possível explicitar a diferencia que se 
O que temos de mais expressivo e esclarecedor em relação à significação metafísica do conceito de compaixão, o que seria de fato uma hermenêutica tendo em vista o seu papel na ética schopenhaueriana e o liame existente entre ele e a significação da conduta moral é a explicação presente nos parágrafos $\S 66,67$ de $O$ mundo como vontade e representação, para onde aponta esboço que compõe o último capítulo da dissertação de 1840.

A interpretação dada nesse contexto explica o fenômeno da compaixão como um dos fenômenos, juntamente com o "amor sexual" e a "magia", por meio dos quais se revela a "identidade metafísica da vontade" ${ }^{, 50}$. A compaixão, portanto, é vista assim como uma manifestação de uma essência eterna, que é anterior aos próprios fenômenos. Isso significa que a compaixão antecede nossa consciência, juntamente com as formas de apreensão da realidade inerentes a esta última. Por isso, podemos comparar o que Schopenhauer escreve sobre o amor sexual, para nos ajudar a compreender o fenômeno da compaixão - embora esse primeiro conduza a afirmação da vontade, enquanto o outro nos leva ao processo inverso. Assim, vejamos o que ele diz sobre esses fenômenos que revelam a própria essência da vontade:

[...] esta essência íntima é justamente a que está no fundamento de nossa própria consciência, como seu núcleo, é por isso mais imediato do que a própria consciência, e, como coisa-em-si, livre do principio individuationis [princípio de individuação], é propriamente a mesma e idêntica em todos os indivíduos, quer eles existam um ao mesmo tempo que o outro ou um após o outro $[\ldots]^{51}$

Observa-se, a partir da afirmação do filósofo, que a coisa-em-si independe da representação. Nesse sentido, é por revelar a vontade como ela é realmente que a compaixão se manifesta independentemente do intelecto, pois é por meio do nosso esquema de representação fenomênica que temos uma ideia ilusória do mundo, por meio do qual a mesma essência parece fragmentada em infinitas formas e intermináveis sucessões. Assim, segundo ele, em alguns momentos, a vontade, ao manifestar-se no

apresenta na ética de Schopenhauer em relação à Geschlechtsliebe e "reinen Liebe", isto é, entre "amor sexual" e "amor puro".

50 Cf. SCHOPENHAUER, A. MVR II, p. 334.

51 SCHOPENHAUER, A. MVR II, tradução de Jair Barboza, p. 54. 
indivíduo, ultrapassa o principio individuationis e reconhece em cada ser vivo imediatamente a sua essência interna.

A compaixão, portanto, suprime o abismo subjetivo que nos causa a ilusão de sermos indivíduos isolados, para que, em alguns breves momentos, possamos nos sentir partes de uma mesma essência. A dor que um indivíduo sente quando presencia o sofrimento alheio mostra que, em determinadas circunstâncias, a vontade, enquanto essência universal, faz prevalecer sua superioridade em relação ao indivíduo, que na maior parte do tempo se limita à realidade presente na representação e permanece restrito à sua subjetividade.

\section{Referências bibliográficas}

BIRNBACHER, Dieter. Arthur Schopenhauer: vontade e negação do mundo. In: FLEISCHER, Margot; HENNIGFELD, Jochem (org). Filósofos do século XIX: uma introdução. Tradução de Dankwart Bernsmüller. São Leopoldo: Editora UNISINOS, 2007.

CACCIOLA, Maria Lúcia M. Oliveira. Schopenhauer e a questão do dogmatismo. São Paulo: Edusp, 1994.

CARTWRIGHT, E. David. Schopenhauer's Narrower Sense of Morality. In: The Cambridge Companion to Schopenhauer. Edited by Christopher Janaway. Cambridge University Press, 1999.

HENRY, Michel. Genealogia da Psicanálise: o começo perdido. Tradução e notas de Rodrigo Vieira Marques. Curitiba: Editora UFPR, 2009.

IRWIN, T. The Development of Ethics: a historical and critical study. Vol III: From Kant to Rawls. Oxford: Oxford University Press, 2009.

JANAWAY, Christopher. Schopenhauer. Tradução Adail Ubirajara Sobral. São Paulo: Edições Loyola, 2003.

PHILONENKO, Alexis. Schopenhauer Una Filosofía de la Tragedia. Traducción de Gemma Muñoz-Alonso López. , Barcelona: Editora Anthropos, 1989.

ROGER, Alain. Atualidade de Schopenhauer. Tradução de Eduardo Brandão In: Sobre $o$ Fundamento da Moral. Tradução de Maria Lucia Cacciola. São Paulo: Martins Fontes, 2001. 
SPIERLING, Volker. Arthur Schopenhauer. Tradução de José Antonio Molina. Herder, Barcelona, 2010.

SCHOPENHAUER, Arthur. $O$ mundo como vontade e como representação. Tradução de Jair Barboza. São Paulo: UNESP, 2005.

. O mundo como vontade e como representação. Tomo II: Complementos. Eduardo Ribeiro da Fonseca. Curitiba: UFPR, 2014.

Sobre o fundamento da Moral. Tradução Maria Lúcia Oliveira Cacciola. São Paulo: Martins Fontes, 2001.

Hedra, 2010.

Sobre a filosofia e seu método. Tradução de Flamarion C. Ramos. São Paulo:

Fragmentos sobre a história da filosofia. Tradução de Karina Jannini. São Paulo: WMF Martins Fontes, 2007.

Da necessidade metafísica. Tradução de Lobo Vilela. Lisboa: Cadernos Culturais Inquéritos, s/d.

Metafísica do amor, metafísica da morte. Tradução de Jair Barboza. São Paulo: Martins Fontes, 2000.

Recebido: 20/12/14

Received: $12 / 20 / 14$

Aprovado: $28 / 01 / 15$

Approved: 01/28/15 